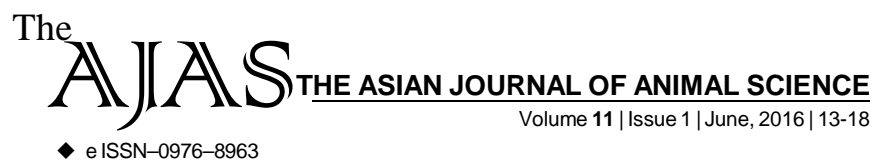

DOI : 10.15740/HAS/TAJAS/11.1/13-18 Visit us | www.researchjournal.co.in $\mathrm{S}$

RESEARCH ARTICLE.

\title{
Effect of level of Jersey inheritance in crossbred cattle on subsequent milk yield
}

ATUL RAI, KULADIP PRAKASH SHINDE AND SHAILESH KUMAR GUPTA . . .

Author for Corresponding -

\section{KULADIP PRAKASH SHINDE}

Division of Livestock Production and Management, ICAR- NDRI, KARNAL (HARYANA) INDIA Email: kuls164@gmail.com

See end of the article for Coopted authors'
ABSTRACT...... This study was conducted to see the effect of level of Jersey inheritance in cross bred cattle on subsequent milk production. The data subsequent milk production of Jersey (J) and Red Sindhi (RS) cows maintained at dairy farm, Sundersan School of Animal Husbandry and Dairying, Sam Higginbottom Institute of Agriculture, Technology and Sciences Allahabad were recorded form the history sheets of the animals maintained during this period (1930-1962) for the basis of this study. Jersey Sindhi crosses were divided into 4 geneticgroups consisting of 17, 11, 51 and 24 animals in $\mathrm{G}_{1}$ (1/2J X 1/2RS), $\mathrm{G}_{2}$ (3/8 J X 5/8 RS), $\mathrm{G}_{3}(1 /$ $4 \mathrm{~J}$ X 3/4RS), $\mathrm{G}_{4}(1 / 8 \mathrm{~J}$ X 7/8 RS). The effects of Jersey inheritance on subsequent milk production were recorded. Dry period has a non-significant effect on subsequent milk yield in all crosses except in 3/8J X 5/8 RS crosses a significant effect was observed on milk yield only. Therefore, due emphasis should be given to the crosses having exotic inheritance 62.5 per cent for selection and cross breeding.

KEY WORDS...... Cross bred, Jersey, Red sindhi, Lactation

HOW TO CITE THIS ARTICLE - Rai, Atul, Shinde, Kuladip Prakash and Gupta, Shailesh Kumar (2016). Effect of level of Jersey inheritance in crossbred cattle on subsequent milk yield. Asian J. Animal Sci., 11(1): 13-18 (DOI : 10.15740/HAS/TAJAS/11.1/13-18).

ARTICLE CHRONICLE - Received : 20.03.2016; Revised : 19.04.2016; Accepted : 11.05.2016 